\title{
Impact of seasoned equity and private placement disclosures on derivative prices: are the spot and option markets integrated?
}

\author{
Mohamed Ariff* and Fan-Fah Cheng \\ University Putra Malaysia, \\ 43400 UPM, Serdang, Selangor, Malaysia \\ Email: ariff13@gmail.com \\ Email: chengfanfah@yahoo.com \\ *Corresponding author \\ Shamsher Mohamad \\ INCEIF, International Centre for Education in Islamic Finance, \\ Jalan Universiti, \\ Petaling Jaya, Selangor, Malaysia \\ Email: shamsher57@yahoo.com
}

\begin{abstract}
This paper reports evidence of significant abnormal returns in call and put options in the New York Stock Exchange around the disclosure time of two equity funding events. The delta values as risk of options are used to adjust gross returns of calls and puts to obtain adjusted abnormal returns. Theory suggests any stock price increases around private placement announcement dates would make calls to become in-the-money, so call prices should increase: conversely, puts would become out-of-money so put prices should be unaffected. Stock price declines around seasoned equity announcement dates would make put prices to increase since puts become in-the-money: call prices, having become out-of-money, would not change. Further, if the spot to the derivative market price impact is due to both markets being fully integrated, a trading strategy could yield profits. To test this, we apply cointegration and Granger-causality tests: we find there is no predictable spot-to-option-market integration in either direction. The empirical evidence of option price changes reported here and also evidence of no integration provide support for the idea that spot and option prices are being formed independently of each other, therefore prices are consistent with the efficient market hypothesis and the option pricing model.
\end{abstract}

Keywords: announcement effect; spillover; call/put prices; private placement; PP; seasoned equity offering; causality; integration.

Reference to this paper should be made as follows: Ariff, M., Cheng, F-F. and S. Mohamad (2017) 'Impact of seasoned equity and private placement disclosures on derivative prices: are the spot and option markets integrated?', Int. J. Bonds and Derivatives, Vol. 3, No. 1, pp.44-70. 
Biographical notes: Mohamed Ariff is a Professor of Finance at Bond University, Australia and University Putra Malaysia. He is widely considered a specialist on Asian Pacific finance and Islamic finance. Formerly, he served as the elected President of the Asian Finance Association. He is the co-author of Investments and has authored or co-authored 33 other books. His scholarly articles have appeared in leading economics and finance journals.

Fan-Fah Cheng is an Associate Professor. He is teaching finance and doing research in finance in the research university at the University Putra Malaysia. He has published books on bond markets, and has published scholarly articles in accounting and finance in rated journals.

Shamsher Mohamad is a Professor of Finance at the INCEIF established for the purpose of training banking professionals. He has worked previously for a long while and held positions of head and dean before joining the current university. He specialises now in Islamic finance teaching and research.

This paper is a revised and expanded version of a paper entitled 'Impact of seasoned equity and private placement disclosures on derivative prices: are the spot and option markets integrated?' presented at 2013 Australasian Banking and Finance Meeting, Shangri-la Hotel, Sydney, 16-18 December 2013.

\section{Introduction to spillover and market integration}

This paper reports significant changes in the abnormal returns (AR) of call and put options in the US market, with the significant price changes occurring ahead of seasoned equity offerings (SEO) and private placements (PP) announcements made to the New York Stock Exchange, NYSE. Evidence already exists of a momentum spillover from stock to bond market (Gebhart et al., 2005; Chulia and Torros, 2008); accounting earnings effect across markets (Amin and Lee, 1997); volatility and price effects in stock market (Tse, 1999); and volume effect from seasoned offerings (Safieddine and Wilhelm, 1996). There are other studies that document volatility spillover across markets from one country to other countries as well as from bond market to stock markets volatility spillover effect from the US stock to the European stock markets (Baele, 2005), which are studies of non-fund-raising events. ${ }^{1}$ This paper is about fund-raising spillover effect on the derivative markets.

There are studies on several other aspects of funding: example is Huang and Zhang (2011) on market making for SEOs. Impact of earnings announcement and volume effect from SEO has been reported. However, the stock-to-option market spillover effects of two fund-raising events have yet been studied for the US market. Our motivation is to study this aspect as well as potential integration of option and spot markets.

Knowledge of funding announcement impact on the calls and puts could be exploited through a trading strategy to profit in the option markets if the markets are fully integrated in a causal sense. Hence, knowing that a funding event could affect prices, traders could devise profitable trading opportunities, which is of interest to investors. Hence the findings on spillover effects from funding events and evidence supporting market integration are useful first as tests of capital market theories and second for designing trading strategy. The motivation for this research is thus our interest in testing 
the predictions of option theory and also how predictable market reaction could be used to profit investors.

Existing evidence suggests that a significant cumulative abnormal return (CAR) on stocks may be predicted as being consistent with information response when

$1 \quad$ PPs

2 SEOs are routinely disclosed by listed firms: this is elaborated in Section 2 with reference to theories.

The literature on event studies supports a positive abnormal return based on the reasoning that investors act as white knights willing to fund troubled firms, thus PP event should elicit good news effect. A negative abnormal return is predicted since an SEO signals overpricing of the stock involved. The relevant studies supporting these conclusions are: Corwin (2003), Hertzel et al. (2002) and Hertzel and Smith (1993). In this study, we test for a similar positive effect for PPs and a negative effect for SEO disclosure in the NYSE using data over a recent six-year period ending in 2012. The same disclosure dates are used to discover spillover effects across on to the option markets. The test on predictability of inter-market integration is done using latest cointegration and causality tests.

Equity-raising events add huge capital to firms, and their effect on option prices is still unexplored, which means our results would add new knowledge on corporate finance behaviour in addition to the corporate earnings announcement effect in Amin and Lee (1997). The fund-raising events ought to have strong influences on the option prices when the stock prices change at or ahead of the announcement times in the spot market. Safieddine and Wilhelm (1996) reported a significant change in volume traded in options markets at the time of SEOs and there are no studies on PPs.

If trades across two markets are based on spot-and-option-market integration, a profitable trading strategy may be devised to trade in the derivatives at the time of stock market disclosures. This research question may be answered by searching for significant cointegrating vector(s) between the two markets by applying Johansen's (1988) test. The Granger (1988) causality test would further provide verification on the issue of cross-market integration. If evidence exists to support a structured causal relation, then a profitable trading strategy could be designed to trade in the other market using one market's disclosed information. ${ }^{2}$ This would mean investors have a legal channel to profit instead of engaging in moral hazard trades based on insider information, ahead of fund-raising event disclosures. Obviously our prior is that the observed spillover effect is not based on interdependency because such an interdependency would be in violation of efficient market pricing in a very liquid market such as the NYSE in violation of the efficient market hypothesis.

The rest of the paper is organised into six more sections. Section 2 contains a very brief statement of theories predicting concurrent spillover effects from PPs and SEOs as predicted by the established theories relevant to this study: this would assure us that equity-raising event effects in the NYSE are consistent with the literature. In Section 3, the reader will find how this study is designed to utilise data collected from both stock and options markets as required by the hypotheses developed in this section. The cointegration and causality modelling for testing a possible structured relationship for 
integration are explained in this section. The results are presented in Sections 4 and 5 respectively on the price effects in the spot market during 2007-2012 period and the spillover effects in the derivative markets respectively. The finding on market-to-market predictability is reported in Section 6. The paper ends in Section 7 with a conclusion of a strong cross market effect from the stock prices to calls and put prices. There is no evidence of predictability from cointegration and causality tests.

\section{Theories predicting concurrent price effect}

While there has been no attempt to directly test the concurrent spillover from funding announcement effect in the stock market to derivative markets as proposed in this paper, there have been studies of other type of spillover effects such as momentum effect from one market to another. Dean et al. (2010) is a recent example of volatility and return effect from the bond market to the stock markets, not the options market. They use stock market indices and bond indices (not individual stocks as in this paper) and produce evidence of a significant spillover effect across these markets as predicted by the asymmetric information theory (not from information economics as in this paper). There are few reports of volatility spillover effect using not events but ARCH and GARCH models (Hammoudeh et al., 2004).

Safieddine and Wilhelm (1996) is a study of increased volume (not returns) activities in the options market around the time of SEO disclosures. Hence, to our best knowledge, there have been no studies of the obvious flow-through concurrent price effect from the spot market fund-raising corporate events leading to price responses as per theories regarding rights/private offerings on to the derivative markets, nor of price predictability from one market on another market.

The announcement event impact on stock has been studied for a variety of events. The events of concern in this study are PPs and SEOs. Wruck (1989) proposed and others produced evidence of a positive price effect when PPs are announced. Stock price reaction to PP announcements has been shown to be positive by others (see Billett et al., 2011; Anderson and Brooks, 2006). PPs, as opposed to SEOs, because it is claimed PP reduces agency costs-cum-information asymmetry, induces a positive stock price reaction as justified in Wruck (1989). Hertzel and Smith (1993) assert that PP signals issuing firm's undervaluation so announcement of a PP helps to mitigate information asymmetry, so spot stock price increases. It is also argued that improvements lead to positive effect from the close monitoring by institutional and private investors placing their money as PP in firms. The US papers reveal a $3.9 \%$ significant abnormal return to shareholders during the -5 to +1 event days around PP disclosures. Hence, the first hypothesis to be tested is on this PP announcement effect.

Valuation theories (among others, Gordon and Shapiro, 1956; Gordon, 1963) predict stock prices are determined in the long run as in the discounted present value of future streams of net cash flows. For example, a popular stock valuation model is:

$$
S_{t-1}=\frac{D_{t}}{r-g}=\frac{E P S_{t}(\text { Payout })}{r-g}
$$


where $D$ is dividend per share, stock price is $S$ at time 0 , indicated as $t-1$, is the value to be computed as a discounted value of dividends $D$ (defined in the above equation also as earnings, EPS, multiplied by the firm's payout ratio) of an infinite dividend stream discounted by the difference in the discount rate, $r$, and the growth rate, $g$.

When a firm seeks to raise capital through a PP, there is an expectation that the subscribing investors would increase monitoring the management of the issuing firm. That is the reason for the price movement on the basis of investor's increased vigilance, resulting in reduced monitoring costs, so the result is less asymmetric information. Further, institutional investor participation is likely to influence stock prices positively since such investors are likened to white knights having faith that the PP-issuing firms could improve performance under their close monitoring (Wruck, 1989). Thus, the future dividends in the long run are likely to increase from future unexpected increases in EPS with improved vigilance. Would this positive effect spillover from the spot stock market to the calls and puts? A stock price increase would spillover as a positive impact on calls and a negative on puts. PP signals a likely improved valuation from close monitoring by investors. This is the second set of research question to be explored.

Are the calls and put prices affected concurrently to PP disclosures in the spot market? The answer is yes as per the option theory of Black and Scholes (1973). Call and put prices change as predicted by this theory. We now examine the concurrent revaluation of call and put prices to PP disclosures. Options theory suggests that a change in the underlying stock price, $S$, in the option model stylistically presented in equation (2) should induce a positive price effect on calls since the intrinsic values of calls $(S-X)$ would increase when the underlying stock price increases as suggested by the theory:

$$
C\left(S^{+} ; X^{-} ; \sigma^{+} ; R_{f}^{-} ; t-T^{+}\right)
$$

where the predicted directions of price effects are shown in superscripts, with $C$ as the call price, $X$ is the exercise price, $\sigma$ is the standard deviation of rate of return on stock, $R_{f}$ is the risk-free rate, and $t-T$ is the time to maturity of a call option contract. $S-X$ is the payoff that determines if a call is to be exercised. This is also consistent with equation (1). ${ }^{3}$ One could argue that any stock price increases in equation (2) from PP announcements would leads to call price $C$ to increase: this is our next hypothesis because the intrinsic value, $S-X$ of a call, gets larger so call price should increase significantly. The prices of exchange-listed stocks traded in the spot market would have gone up, so the sign on stock price in equation (2) is $S^{+}$.

One could extend the same argument using the put option model [see equation (3)] to propose a concurrent price effect on put prices from fund-raising event:

$$
P\left(S^{-} ; X^{+} ; \sigma^{+} ; R_{f}^{-} ; t-T^{+}\right)
$$

If the underlying stock price increases due to the effect of PP announcement, then a put contract would become less valuable because a put's intrinsic value declines. This renders the puts to become more out-of-the-money. Put has no value, and so it would not be exercised by the put investor. PP issue, which is known to increase the underlying stock price, $S$, would render a put worthless so that there should be no concurrent flow-on effect on to the put prices as shown by $S$. This is the corollary of call price effect on put prices. 
Finally, SEOs have just the opposite effect compared to the PP. SEOs signal to investors that stock prices are already overvalued at the time of SEO, which means that the top management are opportunistically raising cheaper equity when prices are up: Hertzel and Smith (1993). There is sufficient evidence in markets (Corwin, 2003) that the average event effect for SEOs is negative. Thus, the next hypothesis to be tested is that a potential price decline of $S$ as in equation (1) would increase the cost of capital, hence the required rate of return, $r$, in the equation increases. In the option market, the intrinsic value $C$ of a call contract would decline, which would make the call worthless. Hence, returns on calls at the announcement time would have to be zero. Conversely, as per equaiton (3), a decline in stock price $S$ from SEO would make the put contract, $P$, worth more, hence the payoffs to put-holders would increase. This is the final hypothesis for rights issue effect on stock prices at the SEO disclosure time.

In summary, theories on stock and option pricing predict a cross-market spillover effect from PP and from SEO as funding events. If evidence of cross-market effects as proposed by these theories is found, there is a possibility that there is a structured relation between the spot and the derivative markets being integrated. Could such a structured relation be used to design a strategy for a profitable trading in derivative markets? This is especially of interest to investors since existing evidence points to increased trading volume in derivative market at SEO disclosures (Safieddine and Wilhelm, 1996). To address this research question, we adopt a test for a cointegrating relationship between markets. Failure to find support for a cointegrating vector would mean there is no interdependent relation. Granger (1988) causality method is also a robustness test of this relationship. Hence, the second research question is for a structured relationship of a predictable linkage across markets.

\section{Research design, hypotheses and models}

\subsection{Research design}

The widely-applied event study methodology (Brown and Warner, 1985; MacKinlay, 1997) is a reliable method to study the impacts of disclosures of news on spot markets: by extension also on the call and put markets. From this method, we compute first the AR, and then the CARs over different test windows, as is the well-established procedure applied in the literature. The same method is adapted slightly to measure abnormal and CARs of calls and puts using option risk measure to scale the gross returns of calls and puts.

The tests are carried out using data over the period 2007-2012 using NYSE market data. Data are collected from electronic data sources in the Exchange for a six-year period that included the period of Global Financial Crisis. ${ }^{4}$ Studying the pricing behaviour during this most turbulent six years could reveal if the stock return behaviour is similar to previously-verified evidence at normal times: as will be seen later as shown in the results section, theory holds in the crisis period. The research design (Figure 1) is based on the assumption [as in Amin and Lee (1997) for earnings disclosures]: see Figure 1 that examination of price behaviour to news of PP and SEO events may provide evidence of cross-market flow-on effects. 
Figure 1 Time line for concurrent event date identification (see online version for colours)

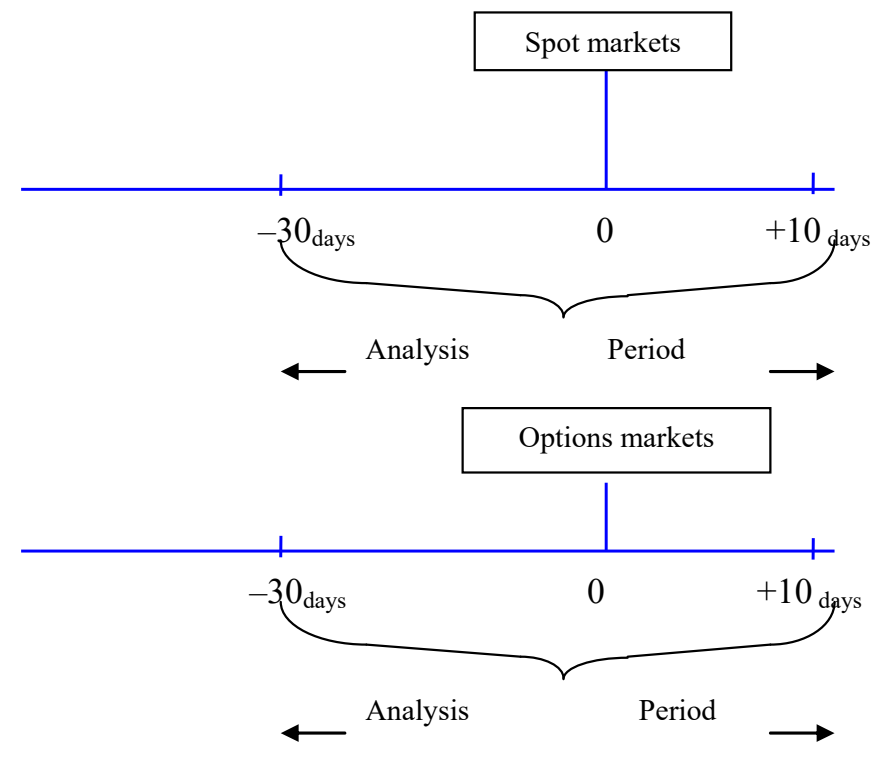

Such a research design to study concurrent cross-market effect would provide double corroborating evidence, one from PP, and another from SEO disclosure as well as what the theory predicts as opposite behaviour of calls and puts.

An event's economic impact in the spot market is observed over a relatively short time period: it is also for the call and put markets, assuming the prices are efficiently formed in both the spot and the option markets. We computed the ARs and CARs over a long period of 30 days before the announcement date and 10 days thereafter, but then found a very strong event impact just few days around the announcement windows. Given the reported evidence of a positive PP issue effect in the US market, it is arguable that an increase in the spot price to a PP disclosure would prompt investors with exercisable options on a respective stock to revalue the call and put prices in the derivative markets.

Increased/decreased spot stock prices would increase/decrease the in-the-money/ out-of-the-money value of call options. Likewise, the put price will have more/less value when the spot price increases/decreases. The verified dates of PP and SEO disclosures as reported in the datasets are assumed to be the 'quasi-event' dates for the calls and puts: see Figure 1 for an explanation. Figure 1 is an illustration of concurrent effects in the spot and the options markets over the observation period -30 to +10 days around the announcement day 0 . From the way prices actually behave, we hope to narrow the measurement of price effect to shorter periods than the one shown in Figure 1 if the prices actually react faster, closer to the zero dates.

Some notation and time line are first defined to facilitate the measurement and analyses of AR. The variable is computed from adjacent daily prices across -30 and +10 days to compute the AR over -29 and +10 days at each PP and then also the SEO disclosure dates. Note carefully that the actual event date on the equity issuance days become the quasi-event dates for the calls and puts. 


\subsection{Hypotheses}

The null hypotheses arising from fund-raising events and the spillover from these events are:

$\mathrm{H}_{1} \quad$ There is no information effect on the stock price at the time of PP disclosures by the US firms listed and traded in both the spot and the options markets.

$\mathrm{H}_{2}$ There is no concurrent spillover price effect on the call option contracts traded in the US options market at the time of disclosures of firm's PP disclosures.

$\mathrm{H}_{3}$ There is no concurrent spillover price effect on put option contracts traded in the US options market at the time of disclosures of firm's PP disclosures.

$\mathrm{H}_{4} \quad$ There is no information effect on the stock price at the time of seasoned equity offer (SEO) disclosures by the US firms listed and traded in both the spot and the options markets.

$\mathrm{H}_{5}$ There is no concurrent spillover price effect on call option contracts traded in the US options market at the time disclosure of SEO disclosures.

$\mathrm{H}_{6}$ There is no concurrent spillover price effect on put option contracts traded in the US options market at the time of disclosure of SEO disclosures.

By rejecting the null hypotheses stated above for $\mathrm{H}_{1}$ and $\mathrm{H}_{4}$, we hope to verify if there is theory-consistent price effects in the spot market for PP and SEO disclosures similar to those reported in prior studies as being positive and negative event effects respectively. The predictions of the options theory are not yet tested: these are a positive spillover effect on calls $\left(\mathrm{H}_{2}\right)$ that could be true if the null hypothesis $\mathrm{H}_{2}$ is rejected. Similarly, $\mathrm{H}_{3}$ may be confirmed as true if the null of $\mathrm{H}_{3}$ of a zero spillover effect is not rejected as predicted by theoryfor the puts in the case of PP.

Similar reasoning suggests that the SEOs would have positive spillover effect on puts and a negative spillover effect on calls: we hope to observe a zero spillover effect on calls from SEO disclosures. The puts will have a positive effect $\left(\mathrm{H}_{6}\right)$ as the cross-market spillover effect is opposite that of the calls, which can be confirmed by rejecting the null of $\mathrm{H}_{6}$.

\subsection{Data sources and variables}

\subsubsection{Data and variables}

Data were accessed from DataStream and the electronic data series on calls and puts available in several databases of the New York market. PP dates are obtained from CapitalPlus database. The US exchange-listed firms with options on their stocks are first identified from the option market lists, and then checked against the data available in the DataStream and other sources. Then the call option, put option and stock prices of individual firms as well as the S\&P 500 index values are collected for a period starting -30 days before and +10 days thereafter. The data collected consist of 234 event observations over 2007 and 2012 consisting of 140 PPs and 94 SEOs that we could find with daily traded prices in the spot and option markets in the NYSE. For calls and puts, we chose only those prices that had trades in both markets and these observations were 
matched to the PP and SEO samples. This sample includes data over 2008-2009 crisis years, and the final samples are modest in size. The events are selected as long as there are no other firm-specific events during the test window. In this way we eliminated such events as earnings, dividends, etc., to ensure that the sample only represented the PP and SEO events.

The variable computed are: rate of change in individual stock prices as natural logs of stock prices across adjacent days. The rate of change in the market index is also similarly computed as return ratio for estimating risk-adjustment parameters using Sharpe's (1963) market model. The price change for calls and puts are similarly computed as rate of change in adjacent daily market prices. In the latter cases, the settlement prices of calls and puts are used for computing daily returns instead of the closing prices in the case of spot stocks. The implied standard deviation of the returns of call and put prices are computed as measures of risk of the stock for use in computing density functions (delta values) as per the Option Model (1973). The delta values - which reflect the risk of the option contracts - are used to scale the gross returns of calls and of puts to arrive at abnormal call and put returns: this procedure is widely used in practice to assign risk, but has not been used in academic research as far as we know.

By defining an event window to be lengthier than the actual few days over which the prices in NYSE really respond ensured that the event effect is not missed. The computation procedure lets the researchers examine price reactions over -30 to +10 days, first before narrowing the test windows to shorter periods. Returns will be computed as changes in adjacent day prices indexed to event time using $t=0$ as the event date, so the returns are over $t=-29$ days and $t=+10$ days to represent the initial event window for tracing the effects. Student t-statistics is employed for significance testing on the average AR first in the spot market at time $t$ to verify if the stocks of firms listed in the two markets do have the same positive price effect from PPs, and a negative price effect from the SEOs. Once verified, we proceed to measure the gross returns for calls and puts, and then adjust the gross return by scaling it by the size of risk of the option (delta risk) before testing the risk-scaled returns for concurrent event effects on the calls and puts as predicted by the options pricing model of Black and Scholes (1973). ${ }^{5}$

The stock price AR is computed as risk-adjusted returns using the Market Model (Sharpe, 1963). The model for expected return in the [.] in equation (4) is a standard general equilibrium relationship for stock returns. AR are:

$$
A R_{i t}=R_{i t}-\left[\alpha_{i}+\beta_{i} R_{m t}\right]=e_{i t}
$$

With $R_{i t}=\operatorname{Ln}\left(P_{i t} / P_{i t-1}\right)$ and $R_{m t}=\operatorname{Ln}\left(I_{t} / I_{t-1}\right)$ where $I$ denotes S\&P 500 index values and $i$ indicates stock in the spot markets. In addition to the terms already defined, $\mathrm{Ln}$ is natural logarithm and $R m$ refers to market's S\&P 500 composite index return. The estimated market parameters $\alpha_{i}$ and $\beta_{i}$ are from running the ordinary least square regression using the stock and market returns over trading periods, -299 day to -40 days (parameter estimation period) relative to the announcement date.

The test window for computing ARs are over -29 to +10 days, which are then computed as the ARit; the averages are separately done for the PPs and SEOs as two samples. Thereafter, we estimate the AARt (average AR) as the measure of the average event impact across different test periods, $-t_{1},+t_{2}$ : 


$$
A A R_{t}\left(-t_{1},+t_{2}\right)=\sum_{i=1}^{N} A R_{i t}
$$

The AARs respectively for PPs and SEOs are cumulated separately across all smaller test windows as the CARs with CAR starting with the largest test window over the -29 and +10 : see equation (6). Thus, there are two CARs respectively for the two events on which tests for significant price effect would be conducted in the cases of PPs and SEOs. The CAR is:

$$
C A R\left(-t_{1},+t_{2}\right)=\sum_{-t_{1}}^{+t_{2}} A A R_{t}
$$

We now explain the process for the option prices. The gross returns are first computed as $G R_{j t}$ (calls) and $G R_{k t}$ (puts) starting with the -29 and ending in +10 days. For the calls $(j)$ and puts $(k)$ as separate samples, $G R$ is the $\ln$ change return computed as $G R_{j t}=\operatorname{Ln}\left(C_{j t} / C_{j t-1}\right)$ for calls and as $G R_{k t}=\operatorname{Ln}\left(P_{k t} / P_{k t-1}\right)$ where $C_{t}$ and $P_{t}$ are call or put daily settlement prices across time periods $t=-30$ and +10 with $t=0$ event date. The gross returns are then adjusted for risk differences by scaling the GRs by the size of the risk measure of options $\beta_{j}$ (calls) and $\beta_{k}$ (puts). The call and put option risk measures are computed as $\beta_{j}$ : and $\beta_{k}$ respectively as:

For calls : $\beta_{j}=d_{1} \times \beta_{i}$ where $\beta_{j}$ is call risk, $\beta_{i}$ risk of firm $i$

For puts : $\beta_{k}=d_{2} \times \beta_{i}$ where $\beta_{j}$ is call risk, $\beta_{i}$ risk of firm $i$

where the delta values $\left(d_{1}\right)$ and $\left(d_{2}\right)$, are computed using the Black and Scholes formula:

$$
d_{1}=\frac{l b\left(\frac{S_{0}}{K}\right)+\left(r+\frac{\sigma^{2}}{2}\right) T}{\sigma \sqrt{T}}
$$

and $d_{2}$ can be computed also as in $d_{2}=\left(1-d_{1}\right)$.

The AR are estimated for the calls and puts as risk-scaled returns, $R S R_{t}$ over time periods $t=-29$ to +10 days with $t=0$ as the event dates for PPs and SEOs. The returns of the call and put are both scaled by the respective size of risk of the call and put options as in equaiton $(10):^{6}$

$$
R S R_{j t}=G R_{i t} / \beta_{j} \text { for calls and } R S R_{k t}=G R_{k t} / \beta_{k} \text { for calls }
$$

The RSRs are averaged across the sample of observations for calls and puts separately to estimate the average ARSRs for calls and puts across -29 to +10 days:

$$
\begin{aligned}
& \operatorname{ARSR}_{j t}\left(-t_{1},+t_{2}\right)=\sum_{j=1}^{N_{\text {calls }}} R S R_{j t} \\
& \operatorname{ARSR}_{k t}\left(-t_{1},+t_{2}\right)=\sum_{k=1}^{N_{\text {puts }}} R S R_{k t}
\end{aligned}
$$


The ARSR of calls and puts are then cumulated across -29 and +10 days respectively as a measure of the risk-scaled returns of calls and puts:

$$
\begin{aligned}
& \text { For calls: } \operatorname{CRSR}_{j}\left(-t_{1},+t_{2}\right)=\sum_{-t_{1}}^{+t_{2}} \operatorname{ARSR}_{t} \\
& \text { For puts: } \operatorname{CRSR}_{k}\left(-t_{1},+t_{2}\right)=\sum_{-t_{1}}^{+t_{2}} A R S R_{t}
\end{aligned}
$$

These measures are tested for statistical significance using the same test statistics to be defined in the next sub-section relating to test of significance of the PPs and SEOs.

\subsubsection{Test statistics for event effect}

As suggested by MacKinlay (1997), variance of stock returns is computed from AR across each sample of observations for PPs and SEOs in the case of spot markets and again for call and put options as:

$$
\operatorname{var}\left(\overline{A R_{t}}\right)=1 / N^{2} \sum_{i=1}^{N} \sigma_{e i}^{2}
$$

Because population $\sigma_{e i}^{2}$ is unknown, the above estimator is used as variance for each sample across the estimation window for testing the significance of the price changes of stocks (for PPs and SEOs) and calls/puts.

The focus of the above procedure is on the null hypothesis, $\mathrm{H}_{0}$, that the event has no impact on the price since either a mean price effect or a variance effect will represent a violation of the null assumption. The tests on PP and SEO samples (and also on call and put samples) are tests of average effect of information disclosures in the respective markets. It is necessary to amend the test to allow for changing (usually increasing) variance as a result of event effects. To allow for this, we use a cross section of AR to estimate the variance for testing the null hypothesis:

$$
\operatorname{var}\left(A R_{t}\right)=1 / N^{2} \sum_{i=1}^{N}\left(A R_{t}-\overline{A R_{t}}\right)^{2}
$$

Given this variance estimator, which can be calculated for each returns at $t=29$ to $t=10$, the null hypothesis on the measures of price change (PP; SEO; Calls; Puts) is zero can be tested as:

$$
t \text {-statistic }=\frac{A A R_{t}}{\left[\operatorname{var}\left(A A R_{t}\right)\right]^{1 / 2}} * N \sim t \text {-distribution }
$$

The above distribution is approximately normal $\sim(N(0,1))$, when $N$ is large: (Brown and Warner, 1985). The cumulative average return (CAR for spot events; CRSR for calls and puts) over the test windows is then tested using the relevant $t$-test as:

$$
t \text {-statistic }=\frac{C A R_{t}}{\left[\operatorname{var}\left(C A R_{t}\right)\right]^{1 / 2}} * N \sim t \text {-distribution }
$$

In practice, because var (.) is unknown, so the usual sample variance measure for the CARs (CAR; CRSR) in each test window is an appropriate choice. To allow for changing 
variance due to the information disclosure, it is necessary to eliminate the reliance on the past returns to estimate the variance of the aggregated CARs. This is done, as explained, by using a cross section of CARs to compute the test parameters for hypothesis testing:

$$
\operatorname{Var}\left(C A R\left(t_{1}, t_{2}\right)\right)=1 / N^{2} \sum_{i=1}^{N}\left[C A R_{i}\left(t_{1}, t_{2}\right)-\overline{C A R}\left(t_{1}, t_{2}\right)\right]^{2}
$$

Given this variance estimator, the null hypothesis that the cumulative returns are zero (CAR; CRSR) can then be tested by using the usual theory (MacKinlay, 1997). After testing these effects in the spot markets for PP and SEO, we proceed to measure the CARs around the same windows for

1 calls

2 puts.

The rate of change in (1) call and (2) put prices are computed for each date over the test windows as natural $\mathrm{ln}$ of adjacent prices. Since there is no theory of 'AR' for options, we use equation (11) and equation (12) respectively for the average risk-scaled returns and before computing the cumulative risk-scaled returns (CRSR). Risk scaling applies the option pricing model concept of option risk as computed in equation (7) and equation (8).

Finally, we tested the variables to ensure that they are $I(1)$ stationary. The augmented Dickey-Fuller (ADF) tests on price data series showed that the series were non-stationary. Further, tests with first difference (ln change of prices) showed the series to be $I(1)$ stationary. Hence, the variables defined as returns are all stationary.

Table 1 ADF unit roots test results on average AR

\begin{tabular}{lcccc}
\hline Right issue & \multicolumn{2}{c}{ Levels } & \multicolumn{2}{c}{ First difference as $\%$} \\
\hline Constant & No trend & Trend & & Trend \\
\hline Variable & & & -5.0195 & -5.0211 \\
Stocks & -1.02004 & -1.229 & $(0.000)^{* * *}$ & $(0.000)^{* * *}$ \\
& 0.7369 & $(0.6845)$ & $\{0\}$ & $\{0\}$ \\
& $\{1\}$ & $\{1\}$ & -5.8732 & -5.8020 \\
Puts & -1.99468 & -2.1154 & $(0.000)^{* * *}$ & $(0.000)^{* * *}$ \\
& 0.2879 & $(0.1565)$ & $\{0\}$ & $\{0\}$ \\
& $\{2\}$ & $\{2\}$ & -7.0939 & -7.0187 \\
Calls & -1.24735 & -1.6580 & $(0.000)^{* * *}$ & $(0.000)^{* * *}$ \\
& 0.6436 & $(0.4895)$ & $\{0\}$ & $\{0\}$ \\
\hline
\end{tabular}

Notes: The variables are prices of stock, implied volatility of put and call. The results indicate that all the variables expressed as levels have unit root at $I(1)$ so they are non-stationary at level. However, tests on first difference show that the variables are statistically significant at 0.01 probability. This means that for the first different test the $\mathrm{p}$-value is less than 0.01 ( $\mathrm{p}$-value $<0.05$ ). The result suggests that one should reject the null hypothesis of non-stationarity at $I(1)$ first difference. Hence, the variables entered as first differenced returns series are stationary, hence the cointegration tests performed is in order.

*** denote significant at 0.01 significant levels, the figure in the parenthesis ( ) refers to $p$-value. \{\} denotes the selected lag length using Schwarz information criterion (SIC). 
Table 1 ADF unit roots test results on average AR (continued)

\begin{tabular}{lcccc}
\hline Right issue & \multicolumn{2}{c}{ Levels } & \multicolumn{2}{c}{ First difference as \% } \\
\hline Constant & No trend & Trend & No trend & Trend \\
\hline Variable & & & & \\
Stocks & -0.77829 & -1.9523 & -4.3455 & -4.3238 \\
& $(0.8144)$ & $(0.3450)$ & $(0.000)^{* * *}$ & $(0.000)^{* * *}$ \\
& $\{1\}$ & $\{1\}$ & $\{0\}$ & $\{0\}$ \\
Puts & -2.91607 & -2.8450 & -5.3454 & -5.2766 \\
& $(0.0524)$ & $(0.103)$ & $(0.000)^{* * *}$ & $(0.000)^{* * *}$ \\
& $\{2\}$ & $\{2\}$ & $\{0\}$ & $\{0\}$ \\
Calls & -1.60878 & $-1.7349)$ & -5.1272 & -5.8835 \\
& $(0.4684)$ & $(0.3946)$ & $(0.000)^{* * *}$ & $(0.000)^{* * *}$ \\
& $\{1\}$ & $\{1\}$ & $\{0\}$ & $\{0\}$ \\
\hline
\end{tabular}

Notes: The variables are prices of stock, implied volatility of put and call. The results indicate that all the variables expressed as levels have unit root at $I(1)$ so they are non-stationary at level. However, tests on first difference show that the variables are statistically significant at 0.01 probability. This means that for the first different test the $\mathrm{p}$-value is less than 0.01 ( $\mathrm{p}$-value $<0.05$ ). The result suggests that one should reject the null hypothesis of non-stationarity at $I(1)$ first difference. Hence, the variables entered as first differenced returns series are stationary, hence the cointegration tests performed is in order.

*** denote significant at 0.01 significant levels, the figure in the parenthesis () refers to $p$-value. \{\} denotes the selected lag length using Schwarz information criterion (SIC).

\subsection{Cointegration/causality on market independence}

Assume that the proposed disclosure effects of PPs and SEOs on calls and puts respectively are shown to be significant. Under this condition, it is worthwhile for a trader to design trading strategies to exploit a predictable dependence of one market on another. Johansen's (1988) cointegration test and Granger (1988) causality test are appropriate to test if the market interdependence is structural so is predictable. If there is no causality, then it is not possible for a trader to devise profitable strategies for trading across the markets. The cointegration model is:

$$
x_{t}=A_{1} x_{t-1}+A_{2} x_{t-2}+\ldots+A_{k} x_{t-k}+u_{t}
$$

where $x_{t}$ is a $(n \times 1)$ matrix, and each of $A_{i}$ is a $(n \times n)$ matrix of parameters; $x_{t}$ represents price observations with $x_{t}=S_{i}$ for stock price at time $t ; S_{j}$ for $j=$ call; $P_{k}$ for $k=$ put prices. This can be retranslated into a vector error correction (VECM) form:

$$
\Delta x_{t}=\sum_{i=1}^{k-1} \Gamma_{i} \Delta x_{t-i}+\Pi x_{t-k}+u_{t}
$$


where $\Gamma_{i}=-\left(I-A_{1}-\ldots-A_{i}\right)(i=1, \ldots, k-1), \Gamma_{i}$ are interim multipliers, and $\Pi=-\left(I-A_{1}-\ldots-A_{k}\right)$. Testing for cointegration is based on the rank of $\Pi$, that is finding the number of $r$ linearly independent columns in $\Pi$ (cointegration vectors): $\Delta x$ represents change in the price series as $\Delta S_{i}$ for stocks: $\Delta C_{j}$ for calls; and $\Delta P_{k}$ for puts across time.

Granger causality test is the next appropriate model to verify a causal relation between any two markets. The existence of causality between returns in the spot and the returns in the option markets is being tested. The VECM model describes the feedback process of deviations between any two markets adjusting towards a long-run equilibrium. Short-run deviations from the long-run equilibrium will feed back on the changes in the dependent variable, in order to force the movement towards a long-run equilibrium. The VECM is a dynamic model of the differenced $I(l)$ variables included in the cointegrating vector and could therefore provide significant insights into the lead-lag behaviour between stock and options markets:

$$
\begin{aligned}
& \Delta y_{t}=\alpha_{1}+\sum_{i=1}^{m_{1}} \beta_{1 i} \Delta y_{t-i}+\sum_{i=1}^{m_{2}} \beta_{2 i} \Delta z_{t-i}+\gamma_{1} x_{t-1}+u_{1 t} \\
& \Delta z_{t}=\alpha_{1}+\sum_{i=1}^{m_{3}} \beta_{3 i} \Delta z_{t-i}+\sum_{i=1}^{m_{4}} \beta_{4 i} \Delta y_{t-i}+\gamma_{2} x_{t-1}+u_{1 t}
\end{aligned}
$$

If $y$ (stocks) Granger cause $z$ (call), then changes in y should precede changes in $z$ and past values (lags) of $y$ are statistically significant in explaining current $z$ : $\Delta$ indicates first difference variable for stock with $\Delta y=\Delta S$ whereas $\Delta z$ is either for $\Delta C$ or $\Delta P$. The cointegrating vector $x_{t-1}$ is the error correction term (ECT) that ensures deviations from long-run equilibrium are corrected gradually through a series of the coefficients $\gamma_{1}$ and $\gamma_{2}$ determining the speed of adjustment back to the long-run equilibrium.

\subsubsection{Hypotheses}

The major cointegration hypothesis is for a strong relationship between stock prices around the disclosure events to affect the call and put variables over the windows -29 to +10 days during the announcement events dates of PPs and the SEOs. Similarly, a causal relationship between markets could be tested using Granter causality tests. Thus, we proceed in this paper to test for predictable linkage by testing the following hypotheses:

H7 There is no cointegration between the stock and call option or between stock and put option markets against the alternative that there is at least one cointegrating vector in one or more cases of PPs and SEOs.

This test is done repeatedly for stock to calls, then stock to puts and finally between calls and puts using samples of PPs and SEOs respectively. Conducting the causality tests similarly is based on the following hypothesis:

H8 There is no causality running from stocks to calls, stocks to puts and calls to puts in the cases of PPs and SEOs. Option Pricing model suggests that there would be causality between calls and puts because of the put-call-parity condition in the model. 
Proof of existence of cointegration alone is sufficient to show the existence of a profitable trading strategy for profitable trades in the option markets. However, establishing a causal relationship lends credibility to such a trading strategy, and is our robustness testing. Insider trading in spot markets with prior inside information is commonly known to lead to profitable trades, under moral hazard condition. However, it will be worthwhile to first show if cointegration exists or not and second if causality exists or not to verify predictability on how trading strategy may be devised for profits.

\section{Findings on equity funding disclosure effects}

This section is devoted to the presentation of results and their interpretations. If the prices of stocks go up at the concurrent disclosure dates of PP issues, the puts written on the stock would become worthless, and hence a zero average put price effect is predicted: the reverse is true of calls. If there exists a cointegrated relationship between the spot and the option markets, markets are then integrated, so a conclusion is valid that there exists profitable trading opportunity.

The findings are presented in a particular order. The PP and SEO spot price effects in the six-year (a period of turbulent market condition in the NYSE) are verified first before presenting concurrent effect on derivative market, which is the focus of this paper. The trading strategy analysis is presented in Section 6.

\subsection{Descriptive statistics}

The descriptive statistics are summarised in Table 2.

Table 2 Descriptive statistics of the calls, puts, stock prices and market index values around event dates in NYSE, 2007-2012

\begin{tabular}{lcccc}
\hline \multicolumn{5}{c}{ Panel A: private placements } \\
\hline & Call $(\$)$ & Put $(\$)$ & Stock price $(\$)$ & S\&P500 \\
\hline Mean & 0.347 & -0.357 & 56.35 & $1,157.9$ \\
Median & 0.294 & -0.306 & 43.71 & $1,177.7$ \\
Standard deviation & 0.177 & 0.175 & 56.76 & 156.1 \\
Minimum & 0.149 & -0.153 & 3.21 & 822.9 \\
Maximum & 1.314 & -1.211 & 420.07 & $1,426.6$ \\
\hline
\end{tabular}

Notes: Table 2 is a summary of descriptive statistics of the options on call, puts, stock prices and the market index during the announcement dates. The total data consist of 230 observations of PP (140) and SEOs (90). The values are taken on the days of announcements. The stock prices are in US dollar while the market index values are in index points, not returns.

The statistics reveal that the average stock price on the respective event day is $\$ 56.35$; calls are priced at an average price of $\$ 0.347$ while puts are priced at $\$ 0.357$ while the average $\mathrm{S} \& \mathrm{P}$ index value is $1,157.9$ points. Stock price statistics on standard deviation is in dollar value here, and not in rate of return. 


\subsection{Disclosure effects in spot markets}

The statistics on the CARs for PP and SEO events are summarised in Table 3. ${ }^{7}$ These statistics are computed over five different test windows, including the most common -1 to +1 windows. The CARs for different test windows are calculated for each day over the -29 and +10 days, and then over shorter windows $-t_{1}$ and $+t_{2}$. By carefully shortening the test window repeatedly, we narrowed the test windows to five days as shown in Table 3 and Figure 2. The CAR for -5 and +1 and CAR for -1 and +1 are statistically significant although the risk adjusted returns are small. The t-value for the former is 1.816 which is acceptable at the probability of 0.10 while the CAR for the shorter and more appropriate -1 and +1 test window is also significant at 0.01 probability level.

Table 3 Tests of significant on market adjusted CARs for PP and SEOs in NYSE, 2007-2012

\begin{tabular}{|c|c|c|c|c|c|}
\hline \multicolumn{6}{|c|}{ Panel A: private placements } \\
\hline & $C A R(-15,+5)$ & $C A R(-10,+5)$ & $C A R(-5,+5)$ & $C A R(-5,+1)$ & $\operatorname{CAR}(-1,+1)$ \\
\hline & 0.031 & 0.027 & 0.050 & 0.055 & 0.050 \\
\hline SD & 0.0851 & 0.0808 & 0.0659 & 0.0521 & 0.0363 \\
\hline t-test & 0.6347 & 0.5704 & 1.3134 & $1.816^{*}$ & $2.379 * *$ \\
\hline \multicolumn{6}{|c|}{ Panel B: seasoned equity offers } \\
\hline & $\operatorname{CAR}(-10,+1)$ & $C A R(-5,+5)$ & $C A R(-5,+1)$ & $C A R(-1,+1)$ & $\operatorname{CAR}(-1,0)$ \\
\hline & -0.0013 & -0.0089 & -0.0120 & -0.0157 & -0.0170 \\
\hline SD & 0.2082 & 0.2601 & 0.2068 & 0.0960 & 0.0712 \\
\hline t-test & -0.0439 & -0.2502 & 0.4238 & -1.1896 & $-1.7425^{*}$ \\
\hline
\end{tabular}

Notes: Table 3 provides the test results on the first event as the market adjusted cumulative abnormal returns computed from abnormal returns for 114 private placements. The return to announcement is measured as the change in stock prices over five windows as shown in Table 3 . The negative sign on the date denotes the days prior to announcement. The positive sign denotes the days after announcement. The CAR $\left(-t_{1}\right.$ and $\left.+t_{2}\right)$ is the sum of the abnormal returns in the windows between $-t_{1}$ days prior to and $+t_{2}$ days after announcement. SD is the standard deviation. The total number of observations is 140 private placements. $*$ and $* *$ indicate significance at 0.10 and 0.05 levels.

Recall that one PP study, cited in the introduction section, using a large sample over a less turbulent period reported stock prices go up by $3.8 \%$. The price change in our study is about $5 \%$, which is slightly larger (and perhaps also due to the crisis) during the more turbulent market condition of our test period. This can be explained as the average event effect of firms included in this study compared to the much diversified firms in prior studies. As can be observed, there is evidence of a consistent positive price effect however long or short the event window chosen.

The plot of the price reactions around the event date suggests that the stock prices are rather flat till the event impact begins from -5 days prior to the announcement date (Figure 2). 
Figure 2 AR of PP in NYSE, 2007-2012 (see online version for colours)

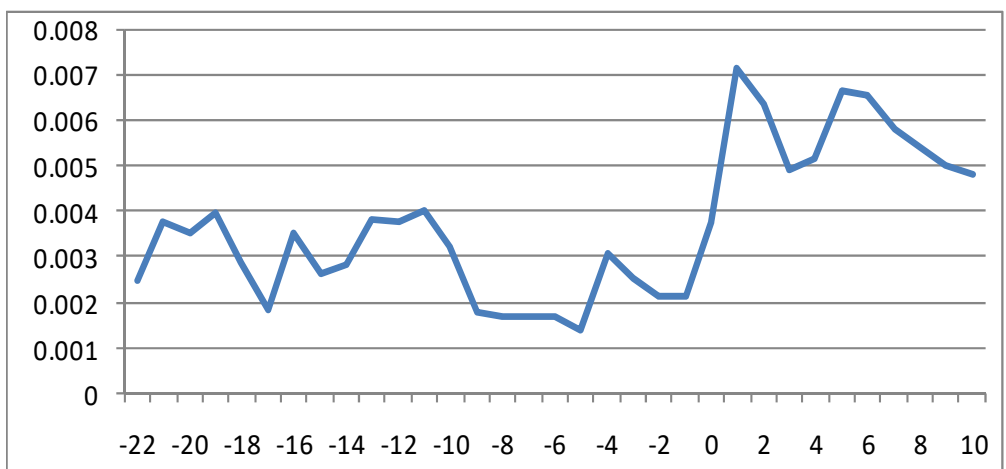

Notes: Figure 2 is a plot of AR over -22 and +10 days relative to the disclosure dates of PP. It reveals that the NYSE firms issuing new equity in this manner gain significant increase in stock prices around the time of announcements.

Prices react quickly going up from about a level to a higher daily abnormal return of about $+5 \%$ by day +1 . Thereafter, the prices go up, but then stabilise at around $5 \%$. Despite the volatile nature of price changes during the Global Financial Crisis and the European Union debt crisis, the CARs are still positive as predict ted by Wruck (1989). The effect tends to not come to an abrupt end after the first few days of announcement as can be seen in the graph. The effect lingers on for few days after the event. This may be due partly to the small sample problem, and perhaps also partly to the period-specific behaviour. If one accepts the prices on day +2 , then the PP effect is about $5 \% \mathrm{AR}$, on average.

The findings on the SEOs are presented also in the same Table 3 in panel B and plotted in Figure 3. This period is not a popular era for equity capital raising for the simple reason of the two crises mentioned before, which meant only few firms raised capital during the test period: the market index went down to about 6,500 in 2008 and lingered below 10,000 index points right up to 2012, when it started to move up. Thus, equity issuing firms would incur high equity cost to raise funds during this economically anaemic period, hence the sample is small compared to that on PPs, which were slightly more frequent in this period when firms sought institutional and private investors rather than issue rights.

All the CARs for all the periods are negative with the CAR over 0 and +1 day being significantly negative: $t$-value of -1.7245 . Given the smaller sample size in this study, it may be argued that the price reaction for these larger dual-market listed firms is rather muted whereas the CARs reported in the prior spot market studies on SEOs without filtering them for option market listing. The effects are much larger in earlier studies than the $-1.7 \%$ observed ( -0.017 in the last column) for the test window over -1 and 0 days during this period. As seen in the plot in Figure 3, the average spot prices of firms announcing SEOs appear to decline slowly so the CARs starts to dip from around day -10 days then again around -3 days as if the investors are anticipating SEOs. However, the prices go up just around -4 days and -3 days. The prices continue to decline thereafter from -2 days to end lower on +10 days. The day -8 registered the highest fall in price with about $-2 \%$ price decline, which, in this study, is the average price reaction of the stocks in the SEO sample. 
Figure 3 AR of SEOs in NYSE, 2007-2012 (see online version for colours)

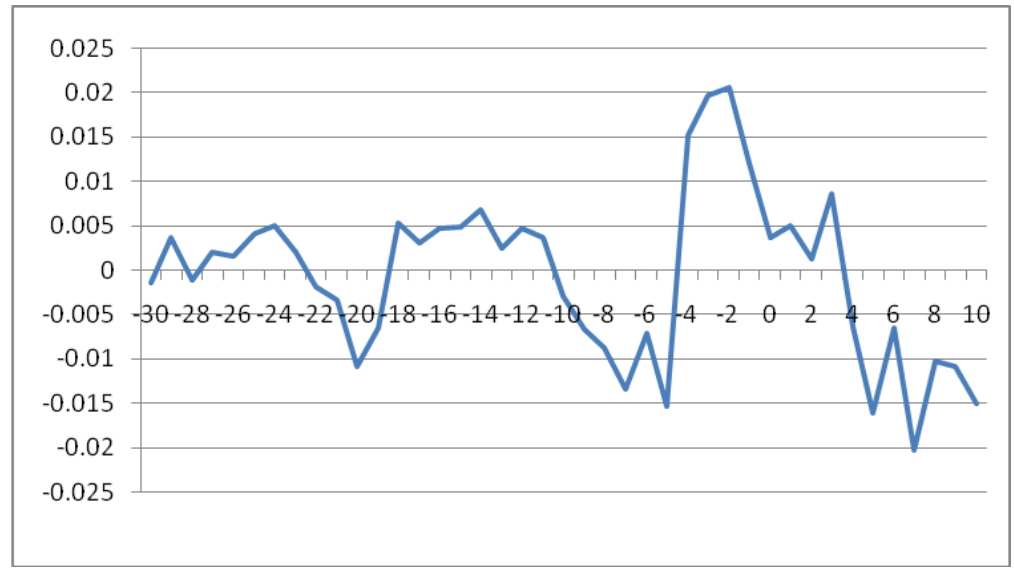

Notes: Figure 3 is a plot of the AR measured over -30 and +10 days of the disclosures of SEOs in the NYSE. The plot show that, over the test window, the stock prices decline significantly, and that during most of the time returns hover around zero

Summary of results from spot markets: these results would suggest that the null hypotheses $\left(\mathrm{H}_{1}\right.$ and $\left.\mathrm{H}_{4}\right)$ relating to spot market prices are rejected at the usual acceptance levels of significance. The price effect is significantly positive for PPs with about $5 \%$ price increase: the price decline for SEOs is close to $-2 \%$.

\section{Spillover effects in options markets}

\subsection{From $P P$}

The findings on spillover effects in the options markets are summarised in this section for the PP events and in the next sub-section for the SEO events. First, we present the results for calls and puts: Table 4 panel A and Figure 4. The test windows are the same as the ones in the spot markets. Recall the hypotheses predicting a positive effect on calls $\left(\mathrm{H}_{2}\right)$ and a zero effect on put $\left(\mathrm{H}_{3}\right)$. The size of the effect on calls is very large considering the CRSR or CRSR computed over test windows ranging from $18 \%$ to $28 \%$.

These returns are after adjusting downwards the 'gross returns' if the risk of the call is greater than 1, and adjusting upwards, if the risk of the call is lower than 1. Since the call prices are but a fraction of the stock price (stock price average was $\$ 56.35$ and call price average was \$0.347), it follows then the highly leveraged calls must have a much more magnified price effect than the $5 \%$ in the spot market for the PPs. This is exactly what is observed for call price changes. The call prices appear to move steadily upward particularly markedly from about -3 days before announcements. For example, the CRSR amounts to $24.50 \%$ in the -1 to +5 test window. The plots of these numbers are shown in Figure 4. 
Table 4 CRSR of call and put options around PP in NYSE, 2007-2012

\begin{tabular}{lccccc}
\hline \multicolumn{5}{c}{ Panel A: call options } \\
\hline Returns & 0.2762 & 0.1842 & 0.2450 & 0.2840 & 0.2485 \\
SD & 1.6708 & 1.4405 & 1.2669 & 1.6378 & 1.6228 \\
t-test & $2.2052^{* *}$ & 1.7063 & $2.5800^{* * *}$ & $2.3118^{* *}$ & $2.0426^{*}$ \\
\hline \multicolumn{7}{c}{} & & Panel B: put options & & CRSR (0, 10) \\
\hline Returns & 0.0771 & 0.0480 & 0.0916 & 0.0821 & 0.1150 \\
SD & 1.5468 & 1.5514 & 1.3209 & 1.5615 & 1.4756 \\
t-test & 0.6653 & 0.4130 & 0.9249 & 0.7012 & 1.0399 \\
\hline
\end{tabular}

Notes: Table 4 is summary of tests on the option price effect from stock market events as the market adjusted CARs of the AR for call options returns during the PP announcements. The announcement return is measured as the change in implied volatility over five windows. The negative sign denotes the days prior to announcement. The positive sign denotes the days after announcement. The CRSR $\left(-t_{1}\right.$ and $\left.+t_{2}\right)$ is the sum of the AR in the windows between days prior to $t$ day after announcement. SD is the standard deviation.

Table 4 is summary of tests on the option price effect from stock market events as cumulative returns of the AR for put options returns during the PP announcements. The announcement return is measured as the change in the rate of change in the prices of calls. The negative sign denotes the days prior to announcement. The positive sign denotes the days after announcement. The CRSR $\left(-t_{1}\right.$ and $\left.+t_{2}\right)$ is the sum of the returns in the windows between $\delta$ days prior to $t$ day after announcement. SD is the standard deviation.

$*, * *$ and $* * *$ indicate significance at $0.10,0.05$ and 0.01 levels.

Figure 4 Cumulative returns of calls, puts and returns, 2007-2012, to PP around announcement days in NYSE, 2007-2012 (see online version for colours)

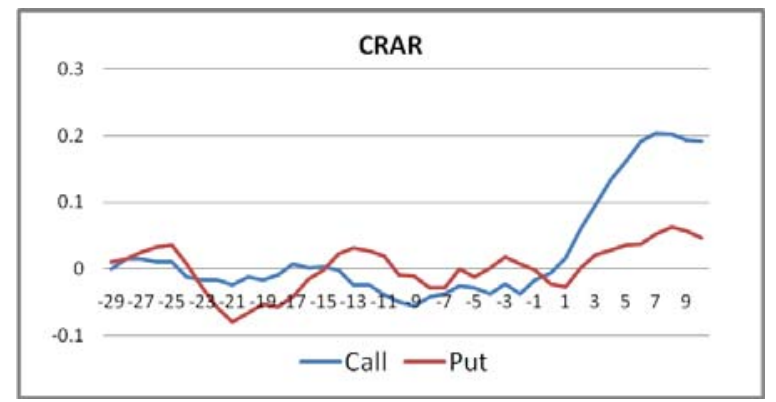

Notes: Figure 4 provides a plot of risk-scaled returns computed from adjusting call and put prices for their riskiness as plotted over announcement window -29 and +10 . It shows a large price reaction in the options markets at the time of PP disclosures. Note option-price-consistent price reactions in the call and put prices as adjusted for riskiness (CRAR). 
There is a statistically significant change with a t-value of 2.58 . The results for the puts are shown in panel B and Figure 4. The put prices appear to react such that, on average, there is no significant change in the risk-scaled cumulative returns in any of the five test windows. Given the theory prediction that stock price increases in response to PP would make the puts out-of-the-money, hence the puts would have to become worthless as is the test result found here. That is what is suggested by the zero effect on put prices, as is also verified by the plot of the CRARs for the puts.

The plots in Figure 4 indicate further a very strong gain for the calls since the intrinsic values had gone up when the stock prices moved up around PP announcements as shown in the previous section. Similarly as predicted, the puts had become worthless as the puts would have gone out-of-the-money. None of the t-values in the five tested windows for puts are statistically significant, so the predicted no price change effect for puts is verified here.

Summary on spillover from PPs: The call values have gone up as spillover effect from spot prices inducing call prices to go up when the underlying stock prices did go up in our sample in response to PPs. Similarly, the put values collapsed when the puts lost intrinsic values when the stock prices went up in response to PPs. The null hypothesis $\left(\mathrm{H}_{2}\right)$ for call is rejected and the null $\left(\mathrm{H}_{3}\right)$ for put is accepted: calls gain value while the puts are worthless.

\subsection{Spillover from SEO}

The cross-market price reactions for the SEOs are summarised and discussed in this section: see Table 5 and Figure 5. First, we examine the price reactions of call contracts using the CRSR in each test window (see Table 5). In opposite ways on how the call prices reacted to PP announcements, the puts gain higher intrinsic values as the stock prices go down around the time of SEOs. The calls appear to have no price effect around the five test windows shown: the t-values reported are insignificant for calls. Although small price reactions are there, none of these is statistically significant. Thus, the null hypothesis $\left(\mathrm{H}_{5}\right)$ is not rejected so there is no spillover price effect on calls. With stock prices going down for SEOs, the calls lose value and become worthless on average, as is consistent with option pricing model.

The intrinsic value, $X-S$, increases for puts. The price reaction as AR ranges from $11.74 \%$ to $40.1 \%$ as in the fourth test window -10 to +1 . The returns for two more windows $(-10$ to +5 ; and -5 to +5$)$ are 29.65 , and $40.05 \%$ respectively, which are statistically significant put price increases. Hence, the null hypothesis $\left(\mathrm{H}_{6}\right)$ is rejected, so we accept the alternative hypothesis of a spillover effect on the puts.

The plots of risk-scaled AR of calls and puts are shown in Figure 5. The price declines in response to SEO disclosures are making the puts go up in value significantly from -1 day to around the announcement day. The price reaction stabilises at about $30 \%-35 \%$ for put contracts. The calls respond with no significant changes to SEO disclosures. 
Table 5 CRSR of the call and put options to SEOs in NYSE, 2007-2012

\begin{tabular}{|c|c|c|c|c|c|}
\hline \multicolumn{6}{|c|}{ Panel A: call options } \\
\hline & $C R S R(-29,+10)$ & $\operatorname{CRSR}(-10,+10)$ & $C R S R(-10,+5)$ & $\operatorname{CRSR}(-10,+1)$ & $C R S R(-5,+5)$ \\
\hline Returns & 0.0189 & 0.1292 & 0.1411 & 0.2051 & 0.0576 \\
\hline SD & 1.3505 & 1.8316 & 1.2671 & 1.2677 & 0.9369 \\
\hline t-test & 0.0999 & 0.5036 & 0.7954 & 1.1555 & 0.4387 \\
\hline \multicolumn{6}{|c|}{ Panel B: put options } \\
\hline & CRSR $(-29,+10)$ & $C R S R(-10,+10)$ & $C R S R(-10,+5)$ & $\operatorname{CRSR}(-10,+1)$ & $C R S R(-5,+5)$ \\
\hline Returns & 0.2528 & 0.1584 & 0.2965 & 0.1174 & 0.4005 \\
\hline SD & 1.1089 & 1.1497 & 1.0684 & 1.0444 & 0.8728 \\
\hline t-test & 1.6285 & 0.9842 & $1.9818^{*}$ & 0.8031 & $3.277 * * *$ \\
\hline
\end{tabular}

Notes: In Table 5, we provide a summary of test results from option markets as the market adjusted CARs of the AR for call options returns during the seasonal equity offering announcements. The announcement return is measured as the change in options prices over five test windows. The negative sign denotes the days prior to announcement. The positive sign denotes the days after announcement. The CRSR $\left(-t_{1}\right.$ and $\left.+t_{2}\right)$ is the sum of the returns in the windows between $-t_{1}$ day prior to and $+t_{2}$ day after announcement. SD is the standard deviation.

In Table 5, we provide a summary of test results from option markets as the market adjusted CARs of the AR for put options returns during the seasonal equity offering announcements. The announcement return is measured as the change in put prices. The negative sign denotes the days prior to announcement. The positive sign denotes the days after announcement. The CAR $\left(-t_{1}\right.$ and $\left.+t_{2}\right)$ is the sum of the returns in the windows between $-t_{1}$ days prior to announcement; $+t_{2}$ around the days after announcement. SD is the standard deviation.

$*$ and *** indicate significance at 0.10 and 0.01 levels.

Figure 5 Risk-scaled AR of calls, puts around SEO dates in NYSE, 2007-2012 (see online version for colours)

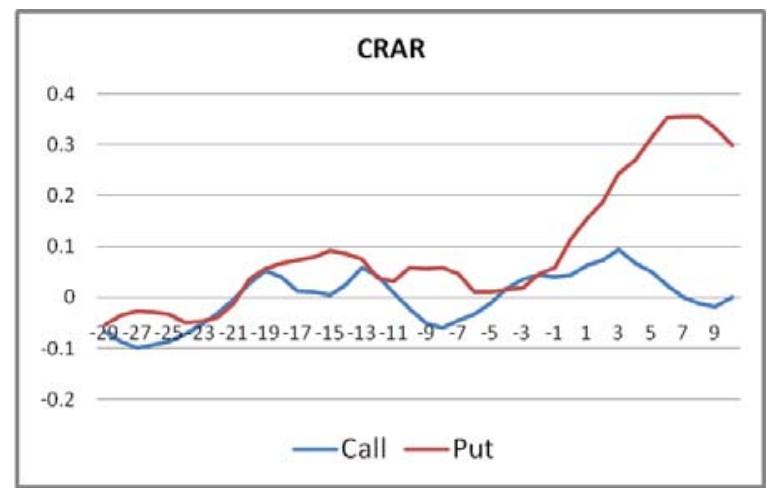

Notes: Figure 5 provides a plot of risk-scaled average returns computed from adjusting call and put prices for their riskiness as plotted over announcement window -29 and +10 . It shows a large price reaction in the options markets at the time of seasoned equity disclosures. Note option-price-consistent price reactions in the call and put prices as adjusted for riskiness (CRAR). 
Summary on spillover from SEOs: the results in this sub-section provide excellent corroborating evidence in support of a spillover effect from SEO disclosures as much as a similar evidence was revealed in the previous sub-section from PP disclosures. Calls react with a zero spillover effect while put contract risk-scaled returns are large and positive as predicted by the option pricing model. The results in this section support a spillover from the spot to the derivative markets.

\section{Market cointegration and causality}

The findings on stock-to-option market integration are summarised in this section. The first set of results is on cointegration test results (Table 6). At least one cointegrating factor has to be significant for cointegration to be proven so that we could assume predictable market interdependence.

The results suggest that (1) there is no cointegration between either stock to call market or stock to put market from PP disclosures as well, similarly from SEO disclosures. That means that the two market price formations are independent of each other, a result consistent with the predictions of efficient pricing, especially when the current and the lagged variables are not significant.

Table 6 Johansen cointegration test results using data over event window -30 to +10 days for $\mathrm{PP}$ and seasoned rights issues in the USA

\begin{tabular}{|c|c|c|c|c|c|}
\hline \multicolumn{6}{|c|}{ Panel A: private placements } \\
\hline & \multicolumn{2}{|c|}{ Hypothesised } & \multirow{2}{*}{$\frac{\text { Trace }}{\text { Statistic }}$} & \multicolumn{2}{|c|}{ Critical value at 0.05} \\
\hline & No. of $C E(s)$ & Eigenvalue & & $\begin{array}{l}\text { Critical } \\
\text { value }\end{array}$ & Probability \\
\hline Stock and call & None & 0.063597 & 3.060537 & 15.49471 & 0.9641 \\
\hline Lag length $=1$ & At most 1 & 0.012685 & 0.497877 & 3.841466 & 0.4804 \\
\hline Stock and put & None & 0.204836 & 9.679179 & 15.49471 & 0.3062 \\
\hline Lag length $=1$ & At most 1 & 0.018799 & 0.740127 & 3.841466 & 0.3896 \\
\hline Call and put & None* & 0.441996 & 23.43449 & 15.49471 & 0.0026 \\
\hline Lag length $=1$ & At most 1 & 0.017343 & 0.682304 & 3.841466 & 0.4088 \\
\hline
\end{tabular}

Notes: Johansen cointegration test results are summarised using data on PP and seasoned rights issues. The stocks and puts appear to have no cointegration since the null hypothesis of cointegration cannot be rejected at the usual critical value of $95 \%$ ( 0.05 p-value). These results for both PP (in Panel A) and seasoned right issues in Panel B would mean that the prices are independently formed without any concurrent of lagged relationship. The results also show that only in the cases of calls and puts (meaning within derivative markets) there is evidence of cointegrating vector(s) according to the asymptotic critical values.

Trace test indicates 1 cointegration equation at the 0.05 level for call and at current and one lag for the put. * denotes rejection of the null hypothesis at 0.05 probability. 
Table 6 Johansen cointegration test results using data over event window -30 to +10 days for $\mathrm{PP}$ and seasoned rights issues in the USA (continued)

\begin{tabular}{|c|c|c|c|c|c|}
\hline \multicolumn{6}{|c|}{ Panel B: seasoned rights issues } \\
\hline & \multicolumn{2}{|c|}{ Hypothesised } & \multirow{2}{*}{$\frac{\text { Trace }}{\text { Statistic }}$} & \multicolumn{2}{|c|}{ Critical value at 0.05} \\
\hline & No. of $C E(s)$ & Eigenvalue & & $\begin{array}{c}\text { Critical } \\
\text { value }\end{array}$ & Probability \\
\hline Stock and call & None & 0.220841 & 12.95218 & 15.49471 & 0.1166 \\
\hline Lag length $=1$ & At most 1 & 0.07925 & 3.220114 & 3.841466 & 0.0727 \\
\hline Stock and put & None & 0.265889 & 13.30678 & 15.49471 & 0.104 \\
\hline Lag length $=1$ & At most 1 & 0.031594 & 1.252068 & 3.841466 & 0.2632 \\
\hline Call and put & None* & 0.235727 & 16.94868 & 15.49471 & 0.03 \\
\hline Lag length $=1$ & At most 1 & 0.152744 & 6.464321 & 3.841466 & 0.011 \\
\hline
\end{tabular}

Notes: Johansen cointegration test results are summarised using data on PP and seasoned rights issues. The stocks and puts appear to have no cointegration since the null hypothesis of cointegration cannot be rejected at the usual critical value of $95 \%$ (0.05 p-value). These results for both PP (in Panel A) and seasoned right issues in Panel B would mean that the prices are independently formed without any concurrent of lagged relationship. The results also show that only in the cases of calls and puts (meaning within derivative markets) there is evidence of cointegrating vector(s) according to the asymptotic critical values.

Trace test indicates 1 cointegration equation at the 0.05 level for call and at current and one lag for the put. * denotes rejection of the null hypothesis at 0.05 probability.

However, there appears to be significant cointegrating vector within the options markets for calls and puts without a lag effect: these are not spillover but within market effects. Option Pricing Model predicts that the calls and puts are opposite of each other, and this result is thus consistent with the theory. Next, the current and lag-one variables show two cointegrating vectors (see the results in the bottom half of Table 6) which are significant at the usual acceptance levels for the options markets. A potential reason for this result is the pricing mechanism used in the market to price these securities. These results may be easily explained as coming from the fact that the call and option prices are dependent on one another and that these are within-market dependence, not spillover effect from spot announcements. What is important for a trading strategy is to find a significant dependence of the call and put options markets on the stock markets from which the disclosed information originates. Lack of evidence on this hypothesis (H7) precludes a profitable strategy for trading (see Table 7).

We now examine the evidence on possible causal relations between markets (see Table 7). The results are summarised in Panel A for the PPs and in Panel B for SEOs. Using pair-wise Granger causality tests, evidence is only for call-to-put linkage, after the clear evidence in the earlier table that there is no cointegration across spot and options markets. The null hypotheses of integration on stock-to-calls and stock-to-puts for PP and SEO respectively cannot be rejected as shown by the test statistics in Table 7. None of the p-values in Table 7 is significant except those between the call-to-put pairs. Hence, the price formation in the stock market and the options market are not Granger-causing each other. Hence, there is no evidence of a predictable causal relation in the US markets between the spot and options (call and put) markets to devise a profitable trading strategy. 
Table 7 Pairwise Granger causality test results using data over event window -39 to +10 days for PP and seasoned right issues in USA

\begin{tabular}{|c|c|c|c|c|c|c|}
\hline \multicolumn{7}{|c|}{ Panel A: private placements } \\
\hline \multicolumn{2}{|l|}{ No. } & \multirow[t]{2}{*}{ Null hypothesis: } & \multicolumn{2}{|c|}{ Observations } & \multirow{2}{*}{$\frac{F \text {-statistics }}{0.56136}$} & \multirow{2}{*}{$\frac{p \text {-values }}{0.5756}$} \\
\hline 1 & Stock & & Call & & & \\
\hline & Call & \multirow{5}{*}{$\begin{array}{c}\text { Does not } \\
\text { Granger cause }\end{array}$} & Stock & & 1.00984 & 0.3749 \\
\hline 2 & Stock & & Put & 140 over & 1.00984 & 0.3749 \\
\hline & Put & & Stock & 40 days & 0.56136 & 0.5756 \\
\hline \multirow[t]{2}{*}{3} & Call & & Put & & 2.39642 & 0.1063 \\
\hline & Put & & Call & & 6.31533 & $0.0047 * *$ \\
\hline \multicolumn{7}{|c|}{ Panel B: seasoned equity offers } \\
\hline No. & & Null hypothesis: & $O b$ & ations & F-statistics & p-values \\
\hline \multirow[t]{2}{*}{1} & Stock & & Call & & 1.76706 & 0.1862 \\
\hline & Call & & Stock & & 0.40498 & 0.6702 \\
\hline \multirow[t]{2}{*}{2} & Stock & Does not & Put & 90 over & 2.04687 & 0.1448 \\
\hline & Put & Granger cause & Stock & 40 days & 0.44925 & 0.6418 \\
\hline \multirow[t]{2}{*}{3} & Call & & Put & & 2.21057 & 0.1252 \\
\hline & Put & & Call & & 0.15288 & 0.8588 \\
\hline
\end{tabular}

Notes: Table 7 is summary of Granger causality test results on stocks-to-calls, stocks-toputs and calls-to put variables. The results are presented in two parts: the top half of Table 7 refers to PP and the rest is for SEOs. Only the call and put price behaviour is significant, meaning that these two option market prices are Granger caused. These findings show that put prices in the case of PP is causing call prices in US market: the p-value 0.004 .

The asterisks ** indicates significance at 0.05 probability.

Summary on inter-market dependence: A strong evidence of positive/negative information effects from $\mathrm{PP} / \mathrm{SEO}$ disclosures is evident in this study respectively around the disclosure dates of these events. The call and put prices react as predicted by the option pricing model around the quasi-dates identified for PP and SEO event disclosures. Tests on trading strategy - hitherto not yet shown for markets - appear to suggest that there cannot be a profitable trading strategy based on either cointegration of these markets nor on valid Granger causality relationship.

\section{Conclusions}

The valuation models (dividend valuation model and option pricing models) predict a cross-market spillover, which has yet been tested for PP/SEO in the US markets. Given evidence of traders shorting options markets in one study cited above (Safieddine and Wilhelm, 1996), is it possible to design profitable strategy in derivative markets ahead of announcements in the spot markets? These are two research questions addressed in this paper. This paper reports findings consistent with the theory-suggested cross-market spillover effects on option markets. First, evidence is found in support of (1) a positive and a negative effect respectively for PP and SEO. Next, the findings suggest that the 
cross-market effect is (2) positive for calls and (3) zero for puts around the quasi-dates of PP disclosures. Conversely, the cross-market effect is (4) zero for calls and (5) positive for puts around the dates of SEOs.

Two econometric tests are conducted to verify whether the spillover effect is based on significant integration between spot and option markets. Cointegrationa and causality tests reveal there is no permanent long term statistically significant spot-to-option linkage. That means that each market is pricing the securities traded therein as per the efficient pricing idea of the news worthiness of the disclosures. Hence, no model-based trading strategy would lead to profits for traders, who act on news of disclosures. We do find strong evidence of calls-to-put market integration within the option markets, which is consistent with the put call parity theorem in the option pricing model.

\section{Acknowledgements}

The first author acknowledges that most of the research for this paper was done while the first author was working at the Bond University. But, the funding for this research was provided under the Maybank Endowed chair at the University Putra Malaysia to fund the expenses and visiting chair position. The authors record the appreciation for the excellent research assistance of Sun Poi-Fa over 2011-2013. The authors acknowledge also a number of our colleagues and participants at staff seminars at Bond University, Griffith University and at the University Putra Malaysia for their comments: also the discussant at the Australasian Banking and Finance Conference in 2013. For an invaluable advice on how to adjust the gross option returns using delta risk, the authors are grateful to Tom Smith of The University of Queensland. The two anonymous reviewers and the Chief Editor provided very useful help to revise the paper as published. The authors are responsible for all errors.

\section{References}

Agarwal, V. and Menenghetti, C. (2011) 'The role of hedge funds as primary lenders', Review of Derivatives Research, Vol. 14, No. 2, pp.241-261.

Amin, K.I. and Lee, C.M.C. (1997) 'Option trading, price discovery, and earnings news dissemination', Contemporary Accounting Research, Summer, Vol. 14 No. 2, pp.153-192.

Anderson, K. and Brooks, C. (2006) 'The long-term price-earnings ratio', Journal of Business Finance and Accounting, Vol. 33, Nos. 9-10, pp.1063-1086.

Baele, L. (2005) 'Volatility spillover effects in European equity markets', Journal of Financial and Quantitative Analysis, Vol. 40, No. 3, pp.373-401.

Billett, M.T., Flannery, M.J. and Garfinkel, J.A. (2011) 'Frequent issuers' influence on long-run post-issuance returns', Journal of Financial Economics, Vol. 99, No. 4, pp.349-364.

Billio, M., Getmansky, M., Lo, A.W. and Pelizzon, L. (2012) Journal of Financial Economics, Vol. 104, No. 4, pp.535-559.

Black, F. and Scholes, M. (1973) 'The pricing of options and corporate liabilities', Journal of Political Economics, Vol. 81, No. 3, pp.637-654.

Brown, S.J. and Warner, J.B. (1985) 'Using daily stock returns, the case of event studies', Journal of Financial Economics, Vol. 14, No. 1, pp.3-21.

Cheng, F.F. and Ariff, M. (2007) 'Abnormal returns of bank stocks and their factor-analysed determinants', Journal of Accounting, Business and Management, Vol. 14, No. 1, pp.1-15. 
Chulia, H. and Torros, H. (2008) 'The economic value of volatility spillover transmission between the stock and bond markets', Journal of Futures Markets, Vol. 28, No. 11, pp.1066-1099.

Corwin, S.A. (2003) 'The determinants of underpricing for seasoned equity offers', The Journal of Finance, Vol. 58, No. 5, pp.2249-2279.

Dean, W.G., Faff, R.W. and Loudon, G.F. (2010) 'Asymmetry in return and volatility spillover between equity and bond markets in Australia', Pacific-Basin Finance Journal, Vol. 18, No. 3, pp.272-289.

Gebhart, W.R., Hvidkajaer, S. and Swaminathan, B. (2005) 'News of spillover in the sovereign debt market', Journal of Financial Economics, Vol. 75, No. 6, pp.691-734.

Gordon, M.J. (1963) 'Optimal investment and financing policy', The Journal of Finance, Vol. 18, No. 2, pp.264-272.

Gordon, M.J. and Shapiro, E. (1956) 'Capital equipment analysis: the required rate of profit', Management Science, April, Vol. 3, pp.102-110.

Granger, C.W.J. (1988) 'Some recent developments in a concept of causality', Journal of Econometrics, Vol. 39, Nos. 1-2, pp.199-211.

Hammoudeh, S., Dibooglu, S. and Aleisa, E. (2004) 'Relationships among US oil prices and oil industry equity indices', International Review of Economics and Finance, Vol. 13, No. 4, pp.427-453.

Hertzel, M. and Smith, R.L. (1993) 'Market discounts and shareholder gains for placing equity privately', The Journal of Finance, Vol. 48, No. 4, pp.459-485.

Hertzel, M., Lemmon, M., Linck, J.S. and Rees, L. (2002) 'Long-run performance following private placements of equity', The Journal of Finance, Vol. 57, No. 4, pp.2595-2617.

Huang, R. and Zhang, D. (2011) 'Managing underwriters and the marketing of seasoned equity offerings', Journal of Financial and Quantitative Analysis, Vol. 46, No. 1, pp.141-170.

Johansen, S. (1988) 'Statistical analysis of cointegration vectors', Journal of Economic Dynamics, Vol. 12, Nos. 2-3, pp.231-254.

Lin, S.X. and Tamvakis, M.N. (2001) 'Spillover effects in energy futures markets', Energy, Vol. 23, No. 1, pp.43-46.

MacKinlay, A.C. (1997) 'Event studies in economics and finance', Journal of Economic Literature, Vol. 35, pp.13-39.

Ritter, J.R. and Welch, I. (2002) 'A review of IPO activity, pricing, and allocations', The Journal of Finance, Vol. 57, Nos. 2-3,pp.1795-1828.

Safieddine, A. and Wilhelm, W.J. (1996) 'An empirical investigation of short-selling activity prior to seasoned equity offerings', The Journal of Finance, Vol. 51, No. 2, pp.729-749.

Sharpe, W.F. (1963) 'A simplified model for portfolio analysis', Management Science, Vol. 9, No. 2, pp.277-293.

Sharpe, W.F. (1964) 'Capital asset prices: a theory of market equilibrium under conditions of risk', The Journal of Finance, Vol. 19, No. 3, pp.425-442.

Tse, Y. (1999) 'Price discovery and volatility', Journal of Futures Markets, Vol. 19, No. 8, pp.911-938.

Wooldridge, J.M. (2001) Econometric Analysis of Cross Section and Panel Data, The MIT Press, Cambridge, London, England.

Wruck, K.H. (1989) 'Equity ownership concentration and firm value', Journal of Financial Economics, Vol. 23, No. 1, pp.3-28.

Wu, X. and Wang, Z. (2005) 'Equity financing in a Myers-Majluf framework with private benefits of control', Journal of Corporate Finance, Vol. 11, No. 5, pp.915-945. 


\section{Notes}

1 The derivative market response to announcements of fund-raising events has yet been studied for any market: Agarwal and Menengehetti (2011) reported hedge fund financing effect not normal listed firms. From a financing point of view, a study on how both stock and option prices react to funding events is valuable to corporate managers, investors, and traders. Non-fund-raising events have been studied by Billio et al. (2012): measuring the connectedness of markets in the financial versus insurance sectors. Price and volatility spillover across the US and 13 European stock markets has been reported in Baele (2005) while news spillover effect is verified across several debt markets when a country's sovereign ratings changes (Gebhart et al., 2005). Evidence of a cross-market dependence of energy prices across the spot and energy futures markets is reported in Lin and Tamvakis (2001). Our study is the first to research spillover effects of two types of funding events relating to equity issuances in the spot market affecting call and put option prices of reporting companies listed in the New York market and their effects on calls and puts.

2 Despite the moral hazard problem of using insider information in trading, it is possible for an insider of the fund-raising firm to use private information from the company to trade ahead of disclosures to make profitable trades in the options markets to make a profit in the USA provided such trades are recorded subsequently as required. We are not examining this issue, preferring to investigate if the structure of spot market to option market interdependence could be used to profit by trading across the market.

3 This way of expressing the theory provides an intuitive explanation to the propositions advanced in this paper. Therefore, to save space and time, the option theory is represented as in equation (2) and equation (3).

4 Conducting the test using data across both crisis and non-crisis period enables the research to note the severity of the price changes. In one sense such a test would prevent spurious results since market prices are known to respond to crisis with a higher volatility and possibly higher mean returns than during normal times.

5 There is no existing theory on how to adjust the gross returns of a call (or a put) for risk differences as has been developed by researchers for the spot market variable using the risk-adjustment procedure in MacKinlay (1997). We acknowledge the invaluable help of Tom Smith of The University of Queensland for suggesting the use of option risk values (deltas) that we finally applied for adjusting the gross return to arrive at risk-adjusted returns for calls and puts.

6 We first measure the stock beta, and then the density function, $d_{1}$ for calls and $d_{2}$ for puts. By multiplying the measure of firm risk and call/put risk [equations (7) and (8)], we computed a risk-adjusted abnormal return for calls and puts. After adjustments, the size of the gross returns of individual call and put reduced by a third, which is as expected.

7 The average abnormal return statistics are available with the authors. Placing those statistics in this paper would lengthen the paper beyond the normal size, hence only the CARs are reported. 